\title{
Emergency care research priorities in South Africa
}

\author{
D J van Hoving, MB ChB, Dip PEC (SA), MMed (Em Med), MScMedSci (Clin Epi); B K Barnetson, MB ChB; \\ L A Wallis, MB ChB, FCEM, MD \\ Division of Emergency Medicine, Faculty of Medicine and Health Sciences, Stellenbosch University, Tygerberg, Cape Town, South Africa
}

Corresponding author: D J van Hoving (nvhoving@sun.ac.za)

Background. Emergency care research is rarely undertaken in low- and middle-income countries. A manageable 'road map' for research in South African (SA) emergency care is needed to address research gaps.

Objective. To identify, collate and prioritise research topics from identified knowledge gaps in emergency care in SA.

Methods. Seventy-six individuals were invited to participate in a modified Delphi study. Participants were requested to suggest important research topics before rating them. Consensus was achieved when $>75 \%$ of participants strongly agreed or disagreed. Participants then ranked the agreed statements before selecting the most appropriate methodology relating to study design, funding and collaboration.

Results. Three hundred and fifty topics were suggested by 31 participants. Topics were collated into 123 statements before participants rated them. Consensus was achieved for 39 statements. The highest-ranked priority in the prehospital group was to determine which prehospital interventions improve outcomes in critically ill patients. The competence of emergency care providers in performing common lifesaving skills was deemed the most important in clinical emergency care. Implementing and reviewing quality improvement systems scored the highest under general systems and safety management. Only 22 statements achieved consensus regarding study design. The National Department of Health was the preferred funding source, while private organisations and emergency care societies were identified as possible collaborative partners.

Conclusion. This study provides expert consensus on priority research areas in emergency care in SA as a guide for emergency care providers to ensure evidence-based care that is relevant to the SA population.

S Afr Med J 2015;105(3):202-208. DOI:10.7196/SAMJ.8967

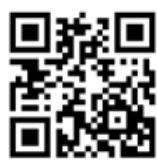

Health research has a high value to society and has resulted in a noteworthy improvement in healthcare. South Africa (SA) has a quadruple burden of disease that is being addressed by the strategic priorities of the National Department of Health $(\mathrm{NDoH}){ }^{[1]}$ A continuous reduction in morbidity and mortality can only be guaranteed if research is ongoing, if the efficacy and adverse effects of medical interventions are continuously monitored, and by ensuring that research is relevant to a specific patient population. ${ }^{[2]}$

High-quality healthcare implies practice that is consistent with the current best evidence. ${ }^{[3]}$ It is essential to know which interventions work and which do not, and which are likely to be harmful. This becomes vitally important in settings with a mismatch between the burden of disease and available resources. While healthcare professionals in low- and middle-income countries (LMICs) should use evidence-based decisions in day-today patient care, implementing evidence-based medicine remains difficult. ${ }^{[4]}$ Since the majority of studies are done in high-income countries for high-income countries relating to health conditions important to high-income countries, ${ }^{[5]}$ their limited applicability and transferability to LMICs creates a knowledge vacuum in LMICs, including SA. ${ }^{[4]}$

Research in the field of emergency care specifically related to LMICs is sparse. A single consensus study related to clinical research priorities, emergency centre management and administration exists, ${ }^{[6]}$ but there are no lists or identified gaps for any aspects of emergency or acute care specific to SA.

Research related to emergency care in SA demands a manageable 'road map' to address the research gaps. This study aimed to identify, collate and prioritise research topics from identified knowledge gaps in emergency care in SA.

\section{Methods \\ Study design}

A three-phase modified Delphi study was undertaken from 1 March 2012 to 5 April 2013. The Delphi study design was modified in that each phase was limited to only two or three rounds (Fig. 1).

Ethics approval was obtained from the Human Research Ethics Committee, Stellenbosch University, Tygerberg, Cape Town (Reference S12/02/034).

\section{Study population}

Seventy-six participants were invited to represent the expert panel (Appendix 1). They included doctors, nurses, prehospital care providers, and policy makers from all the provinces in SA. Invited panel members were given the option of appointing a representative in their place.

\section{Data collection and management}

All potential panel members were invited by e-mail, and participation implied consent. An online survey tool (SurveyMonkey) was used to facilitate the process. The views of all participating panellists were given equal weight. Participants were given 4 weeks to complete each round; weekly reminders were sent by e-mail until a response was received or the 4 weeks had expired.

All panel members were invited to participate in rounds 1 and 2 of phase 1 and re-invited for the first round of phases 2 and 3.

In phase 1 (identifying research topics), participants were requested to suggest important research topics in five categories of emergency care (adult emergency care, paediatric emergency care, prehospital emergency care, emergency nursing care, and a 'general' section for any other area related to emergency care). An example was provided for each category, and categories were randomised to avoid question order bias. The suggested research topics were then collated 
Phase 1. Identifying research topics

- Round 1: Submission of free-text suggestions regarding important research needed in emergency care

- Round 2: Rate agreement of proposed research statements

- Round 3: Determine consensus on research statements

\section{Phase 2. Prioritising research topics}

- Round 1: Ranking of agreed research statements

- Round 2: Determine consensus on ranking of statements

Phase 3. Best approach to prioritised research topics

- Round 1: Select the most appropriate method to address the research statements related to study design, funding and collaboration

- $\quad$ Round 2: Determine consensus regarding most appropriate study design

Fig. 1. The Delphi process used to attain a coherent list of research topics for emergency care in SA.

Table 1. Examples to determine rank order of research statements

\begin{tabular}{|c|c|c|c|c|c|}
\hline & \multicolumn{3}{|c|}{ Ranked value } & \multirow[b]{2}{*}{ Average per statement } & \multirow[b]{2}{*}{ Ranking } \\
\hline & Participant A & Participant B & Participant C & & \\
\hline Statement A & 1 & 2 & N/A & 1.5 & 1 \\
\hline Statement B & 2 & 3 & $\mathrm{~N} / \mathrm{A}$ & 2.5 & 3 \\
\hline Statement C & 3 & 4 & 3 & 3.3 & 4 \\
\hline Statement D & 4 & 1 & 1 & 2 & 2 \\
\hline Statement E & N/A & 5 & 2 & 3.5 & 5 \\
\hline
\end{tabular}

into 123 research statements. Participants were then asked to rate their agreement that each statement was a priority for research in emergency care in SA. A 10-point Likert scale was used, and consensus was achieved when $>75 \%$ of participants strongly agreed (scores 8 - 10) or strongly disagreed (scores 1 - 3). The mean score for each statement was calculated, while statements completed as 'not applicable' were excluded. Surveys were then individualised, and participants were presented with all non-consensus statements. Both the participant's rating score and the mean rating score for each nonconsensus statement were provided to allow participants to consider an alternative rating score.

In phase 2 (prioritising research topics), consensus statements from phase 1 were regrouped into three new categories: (i) prehospital; (ii) clinical; and (iii) general systems and safety. Panellists were asked to rank the statements in each category in order of importance. Categories per se and statements within each category were randomised to prevent question order bias. Participants could exclude statements by indicating them as 'not applicable' to their area of expertise. Submission was blocked until all statements were either ranked or excluded. The overall rank order per category was subsequently determined. For each participant, the first ranked statement (i.e. most important) was given a value of 1 . The lowestranked or least important statement received the value of the number of statements in that category less the number of statements selected as 'not applicable'. An average ranking score was calculated for every statement by adding the values given by all participants, and dividing that by the number of participants that ranked that specific statement; the top ranking statement would therefore have the lowest average score (Table 1).

The ranked statements were presented to the participants. The categories were randomised, but the statements in each category were presented in the order of the average ranking scores achieved. Both the participant's ranking score and the mean ranking score were provided to allow participants to consider an alternative ranking score.

For the final phase (best approach to prioritised research topics), participants were requested to choose one or more study design options. Participants were also given the option of using free text to suggest funding and collaboration options for each statement. Participants were again allowed to select 'not applicable' to exclude themselves from that statement if they considered the topic out of their area of expertise. Only the study design options for each research statement were redistributed to determine consensus.

Collected data were transferred to and analysed on a passwordprotected electronic spreadsheet (Microsoft Office Excel 2010, Microsoft Corporation, USA).

\section{Results}

Seventy-six panel members were invited to participate in the study. Two medical and three nursing panel members appointed 
representatives in their place. The response statistics for all study phases are summarised in Fig. 2.

Three hundred and fifty research topics were suggested by 31 participants $(41 \%)$. The suggested topics were collated into 123 research statements. Seventy-five of the original 76 panel members were invited to rate their agreement of the proposed collated research statements as a priority for research in emergency care in SA (one panel member was responded, and consensus was achieved for 11 statements. The remaining statements were resent for re-rating. Consensus was achieved for 39 statements after 25 participants (81\%) changed their initial scores.

These statements were then grouped into the three categories as described under 'Methods'. One of the statements was only identified late in the study and was subsequently not included. The consensus statements were ranked by 29 panel members (39\%). Statements were re-ordered according to their average ranking scores achieved. The unintentionally not invited). Thirty-one (41\%)

Delphi process used to determine consensus regarding the ranking of the research statements was completed by 19 participants (65\%). Tables 2, 3 and 4 provide the final consensus ranking order of consensus priority statements in each category.

The response rate for suggesting study design options was $28 \%(n=21)$; only three statements initially achieved consensus. The last round of the study (reconsidering study design options) was completed by 15 participants (71\%). An additional 22 statements achieved consensus regarding the most appropriate study design to use (Tables 2 - 4).

One to three suggestions per statement for funding options were received for 32 (84\%) of the 38 statements. The $\mathrm{NDoH}(n=26)$ and private organisations $(n=12)$ were most often indicated as potential funding sources. One to two collaboration suggestions per statement were provided for 29 statements (76\%). Private organisations $(n=7)$ and emergency care-related societies $(n=7)$ were considered as options with which to do collaborative work.

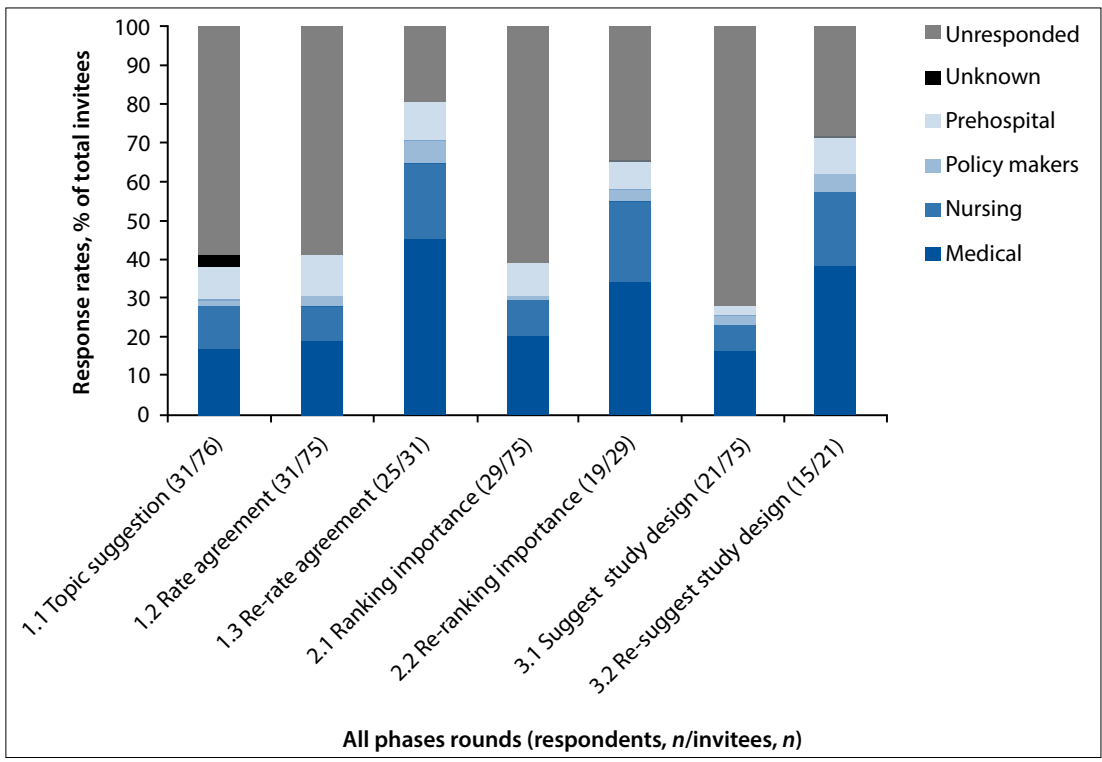

Fig. 2. Summary of response statistics for all study phases.

\section{Discussion}

Thirty-nine statements related to emergency care were identified as high priorities for the SA setting.

\section{Prehospital emergency care}

Prehospital interventions on patient outcomes were ranked first among prehospital research priorities. The need to substantiate clinical care by evidence and to use clinically relevant performance measures was echoed by studies from Europe and the USA, including both adult and child populations. ${ }^{[7-9]}$ There have been substantial international debates regarding the scope of prehospital care, and it is clear that the issue has not been resolved. The SA emergency medical services system has adopted the Anglo-American system, which minimises on-scene time (as opposed to the FrancoGerman model, which includes prehospital physicians with an extensive scope of practice and very advanced technology). ${ }^{[10]}$ A prolonged on-scene time, usually as a result of additional prehospital interventions, has been shown to be detrimental to patient outcomes (especially in trauma); it is therefore important to ensure that only the necessary interventions, backed by substantial evidence, are performed. ${ }^{[1]}$

Appropriate management strategies ranked second in the prehospital group. Any prehospital system faces challenges with the acquisition and appropriate allocation of assets and resources, including human resources. ${ }^{[12]} \mathrm{SA}$ has been losing significant numbers of prehospital practitioners with advanced training over the past decade. ${ }^{[13]}$ Poor working conditions, physical security and economic considerations were identified as some of the main 'push' factors. ${ }^{[13]}$ Govender et al. ${ }^{[14]}$ also hinted that current measures are inadequate to actively manage the shortages of prehospital practitioners with advanced training and their migration out of SA.

\section{Clinical emergency care}

Emergency care (prehospital, medical and nursing) is a procedure-orientated field that

Table 2. Ranked research priority topics related to prehospital emergency care

\begin{tabular}{lll}
\hline Rank & Research statement & Study design \\
\hline 1 & Determine which prehospital interventions improve outcomes in trauma or critically ill patients & Randomised controlled trial \\
2 & Determine the most appropriate prehospital management strategies in southern Africa & Systematic review \pm meta-analysis \\
Tie 3 rd & Optimise the use of resources in terms of transfers and transport in emergency medical services & Non-consensus \\
Tie 3rd & Compile evidence-based guidelines for the critical care transfer of patients & Systematic review \pm meta-analysis \\
5 & Determine the outcomes of prehospital drug-facilitated intubations & Non-consensus \\
6 & Determine an appropriate mass casualty system for southern Africa & Systematic review \pm meta-analysis \\
7 & Implications of the abuse of ambulance services to transport non-emergency cases & Descriptive study \\
8 & Define the role of aeromedical transport in rural areas & Descriptive study
\end{tabular}


Table 3. Ranked research priority topics related to clinical emergency care

\begin{tabular}{|c|c|c|}
\hline Rank & Research statement & Study design \\
\hline 1 & $\begin{array}{l}\text { Determine how competent emergency care providers are in performing common lifesaving skills } \\
\text { within their scope of practice }\end{array}$ & Non-consensus \\
\hline 2 & $\begin{array}{l}\text { Determine whether emergency care providers are competent in recognising and handling a failed } \\
\text { airway }\end{array}$ & Descriptive study \\
\hline 3 & Determine the burden of disease and patient conditions that present to the emergency centre & Descriptive study \\
\hline 4 & Determine how competent emergency nurses are in recognising critically ill patients & Descriptive study \\
\hline 5 & Determine markers of severity in the trauma or critically ill patient & Systematic review \pm meta-analysis \\
\hline 6 & Determine how competent emergency care providers are in providing paediatric critical care & Descriptive study \\
\hline 7 & Develop effective pain management strategies for all acute-care patients & Systematic review \pm meta-analysis \\
\hline 8 & Determine the knowledge and utilisation of non-invasive ventilation by emergency care providers & Descriptive study \\
\hline 9 & Determine the efficacy of nurse-led triage & Non-consensus \\
\hline 10 & Determine the need for a national poison information centre & Descriptive study \\
\hline 11 & Determine appropriate spinal immobilisation techniques in the SA context & Non-consensus \\
\hline 12 & Determine whether paediatric seizures are managed appropriately by all emergency care providers & Descriptive study \\
\hline 13 & Determine whether toxicological cases are appropriately managed by all emergency care providers & Non-consensus \\
\hline 14 & Determine whether paediatric febrile illnesses are managed appropriately & Descriptive study \\
\hline 15 & $\begin{array}{l}\text { Determine the impact of low-dose digital X-ray (LODOX) machines on emergency trauma patient } \\
\text { management }\end{array}$ & Non-consensus \\
\hline
\end{tabular}

Table 4. Ranked research priority topics related to general systems and safety management

\begin{tabular}{|c|c|c|}
\hline Rank & Research statement & Study design \\
\hline 1 & Implement and review quality improvement systems & Non-consensus \\
\hline 2 & Determine whether evidence-based healthcare is adhered to in providing emergency care & Descriptive study \\
\hline 3 & Develop strategies to reduce child and infant morbidity and mortality & Systematic review \pm meta-analysis \\
\hline 4 & $\begin{array}{l}\text { Comparison of the different acute-care systems in order to improve understanding and } \\
\text { implement integrated care pathways }\end{array}$ & Systematic review \pm meta-analysis \\
\hline Tie 5 th & Determine whether lifesaving equipment is checked before commencing duty & $\begin{array}{l}\text { Systematic review } \pm \text { meta-analysis or } \\
\text { descriptive study }\end{array}$ \\
\hline Tie 5 th & Determine the cost-effectiveness of providing emergency care & Systematic review \pm meta-analysis \\
\hline 7 & Determine the true implication of prolonged length of stay in emergency centres & Non-consensus \\
\hline 8 & Determine the impact of National Health Insurance on emergency care & Non-consensus \\
\hline 9 & Determine efficacy of infection control measures in various acute-care settings & Non-consensus \\
\hline 10 & Determine valid and reliable assessment methods for emergency care educational examinations & Non-consensus \\
\hline 11 & Determine the efficacy of hospital case load policies & Non-consensus \\
\hline 12 & $\begin{array}{l}\text { Determine whether informed consent is appropriately undertaken in the emergency care } \\
\text { setting }\end{array}$ & Descriptive study \\
\hline 13 & Determine whether adequate emergency centre discharge instructions are given to patients & Descriptive study \\
\hline 14 & Determine how emergency care trainees perceive their future in emergency care in southern Africa & Descriptive study \\
\hline 15 & $\begin{array}{l}\text { Determine the impact of occupation-specific dispensation on recruitment and retention of } \\
\text { emergency centre staff }\end{array}$ & Descriptive study \\
\hline
\end{tabular}

requires adequate knowledge and skills to diagnose and manage acute aspects of illnesses and injuries. ${ }^{[15]}$ Overcrowding and prolonged length of patient stay mean that the management of critically ill and trauma patients frequently extends beyond initial stabilisation in the emergency centre when intensive care unit capacity is limited (and exhausted). The consequences were reflected in the research priorities related to clinical emergency care, where statements relating to competence in managing critically ill patients featured repeatedly.
However, SA-trained healthcare providers have always been sought after internationally owing to the high quality and standard of their medical education and their hands-on experience. ${ }^{[16]}$ The focus on competence is also in stark contrast to other international studies, which highlighted clinical outcomes as their top research priorities. ${ }^{[17,18]}$ Emergency medicine is still a relatively young specialty in SA, with the focus on competence revealing that it is still establishing its place in the broader medical field. 
The burden of disease and patient conditions presenting to emergency centres ranked third in the clinical emergency care section. Knowing the acuity mix of patients presenting to emergency centres is essential to plan service delivery accurately. The efficient deployment of staff relative to temporal patterns of patient presentations and developing strategies for dealing with non-referred minor cases has been highlighted previously. ${ }^{[19]}$ This information can also help in identifying key areas to optimise patient flow from as early as the initial presentation to the emergency medical service, so that emergencies can be dealt with promptly and appropriately. ${ }^{[19]}$

The emergency medicine setting is a unique environment of high patient volumes, brief clinical encounters, and patients from all age groups representing a spectrum of acuity. Risk stratification is the initial step towards a personalised patient care plan to ensure that patients are safely managed and appropriately investigated. Although the identification of appropriate markers of severity (5th-ranked statement) was identified as an international priority, ${ }^{[17]}$ it would be just as useful, or even more useful, in resource-limited settings. The early identification of disease severity and subsequent focused management of high-risk patients is therefore as important from a healthcare economics point of view as from a morbidity and mortality perspective.

\section{General systems and safety management}

The expectation and requirement to deliver safe and highquality emergency care have never been greater. Healthcare systems are not as reliable as has been thought, and highquality care is often lacking. ${ }^{[20,21]}$ Cost-effectiveness of emergency medical interventions and quality assurance are considered global priorities. ${ }^{[6,21]}$ According to the Institute of Medicine in the USA, a healthcare system should aim to be safe, effective, efficient, patient-centred, timely and equitable. ${ }^{[20]}$ Components of emergency care that can improve quality and patient safety include well-trained and motivated staff, appropriate physical structures, effective processes to enable high-quality care, co-ordinated clinical pathways supported by best evidence-based practice, and monitoring objective outcome measures to reflect continuous quality improvement (e.g. diagnostic errors, mortality and morbidity rates, etc..$^{[22]}$

\section{Study limitations}

Purposeful sampling was used for the panel selection, the criteria being that experts were identified by their specialist qualification and roles as leaders in their fields or heads of academic institutions or societies. Policymakers remained largely non-contactable, limiting the knowledge gained pertaining to policies and resource allocation at provincial or national levels.

Participants in a Delphi study have an interest and involvement in the question being examined. Researcher and subject bias is a known limitation, but the wide range of panellists should offset this. The opinion of a subset of experts with special interests in certain aspects of emergency care (e.g. paediatric emergency care) may have been under-represented.

The lack of participant discussion may have prevented participants from changing their views and responding according to the majority opinion.
Collating free text statements was undertaken in an effort to reduce the number of statements to avoid panel fatigue and attrition. Abstraction may have led to omission of details and potential oversimplification of suggested priority topics.

The response rate and consensus thresholds (75\%) mean that final agreement is not implied; guidelines for further research were essentially identified.

\section{Conclusion}

This study provides expert consensus on the current priority research areas in emergency care in SA. It can ultimately guide emergency care providers to serve the SA population with evidence-based emergency medical care that is relevant.

Acknowledgement. We thank Ms Rachel Allgaier for her input on the initial proposal.

\section{References}

1. Department of Health (South Africa). NSDA: A Long and Healthy Life for All South Africans. Pretoria: Department of Health, 2013. http://www.hst.org.za/sites/default/files/NSDA_booklet.pdf (accessed 24 July 2014).

2. Wallis LA. Knowing and doing: Negotiating resource constraints through research. African Journal of Wallis LA. Knowing and doing: Negotiating resource constraints through research. A

Emergency Medicine 2013;3(4):151. [http://dx.doi.org/10.1016/j.afjem.2013.08.002] 2000;320(7240):954-955. [http://dx.doi.org/10.1136/bmj.320.7240.954]

4. Lowe M. Evidence-based medicine - the view from Fiji. Lancet 2000;356(9235):1105-1107. [http:// dx.doi.org/10.1016/S0140-6736(00)02743-4]

5. Chinnock P, Siegfried N, Clarke M. Is evidence-based medicine relevant to the developing world? PLoS Med 2005;2(5):e107. [http://dx.doi.org/10.1371/journal.pmed.0020107]

6. Hodkinson PW, Wallis LA. Emergency medicine in the developing world: A Delphi study. Acad Emerg Med 2010;17(7):765-774. [http://dx.doi.org/10.1111/j.1553-2712.2010.00791.x]

7. Fevang E, Lockey D, Thompson J, Lossius HM. The top five research priorities in physician-provided pre-hospital critical care: A consensus report from a European research collaboration. Scand J Trauma Resusc Emerg Med 2011;19(1):57. [http://dx.doi.org/10.1186/1757-7241-19-57]

8. Snooks $\mathrm{H}$, Evans A, Wells B, et al. What are the highest priorities for research in emergency prehospital care? Emerg Med J 2009;26(8):549-550. [http://dx.doi.org/10.1136/emj.2008.065862]

9. Foltin GL, Dayan P, Tunik M. Priorities for pediatric prehospital research. Pediatr Emerg Care Foltin GL, Dayan P, Tunik M. Priorities for pediatric prehospital reser
2010;26(10):773-777. [http://dx.doi.org/10.1097/PEC.0b013e3181fc4088

10. Al-Shaqsi S. Models of international emergency medical service (EMS) systems. Oman Med J 2010;25(4):320-323. [http://dx.doi.org/10.5001/omj.2010.92]

11. Seamon MJ, Doane SM, Gaughan JP, et al. Prehospital interventions for penetrating trauma victims: A prospective comparison between advanced life support and basic life support. Injury 2013;44(5):634638. [http://dx.doi.org/10.1016/j.injury.2012.12.020]

12. Institute of Medicine. Challenges facing the prehospital system. In: Preparedness and Response to a Rural Mass Casualty Incident: Workshop Summary. Washington, DC: National Academies Press, 2011. http://www.ncbi.nlm.nih.gov/books/NBK62391/ (accessed 31 July 2014).

13. Govender K, Grainger L, Naidoo R, MacDonald R. The pending loss of advanced life support paramedics in South Africa. African Journal of Emergency Medicine 2012;2(2):59-66. [http://dx.doi. org/10.1016/j.afjem.2011.11.001]

14. Govender K, Grainger L, Naidoo R. Developing retention and return strategies for South African advanced life support paramedics: A qualitative study. African Journal of Emergency Medicine 2013;3(2):59-66. [http://dx.doi.org/10.1016/..afjem.2012.11.005]

15. Emergency Medicine Society of South Africa. Practice guideline EM001 - Definition of emergency medicine. 2008. http://emssa.org.za/documents/em001.pdf (accessed 31 July 2014).

16. Bezuidenhout M, Joubert G. Reasons for doctor migration from South Africa. S Afr Fam Pract 2009;51(3):211-215.

17. Eagles D, Stiell IG, Clement CM, et al. International survey of emergency physicians' priorities for clinical decision rules. Acad Emerg Med 2008;15(2):177-182. [http://dx.doi.org/10.1111/j.15532712.2008.00035.x]

18. Keijzers G, Thom O, Taylor D, Knott J, Taylor DM. Clinical research priorities in emergency medicine. Emerg Med Australas 2014;26(1):19-27. [http://dx.doi.org/10.1111/1742-6723.12141]

19. Hodkinson PW, Wallis LA. Cross-sectional survey of patients presenting to a South African urban emergency centre. Emerg Med J 2009;26(9):635-640. [http://dx.doi.org/10.1136/emj.2008.063362]

20. Institute of Medicine. Crossing the Quality Chasm: A New Health System for the 21st Century. Washington, DC: National Academy Press, 2001. http://www.nap.edu/books/0309072808/html/ (accessed 14 August 2014).

21. Lutge E, Friedman I, Mbatha T. A review of health research in South Africa from 1994 to 2007. In: Barron P, Roma-Reardon J, eds. South African Health Review 2008. Durban: Health Systems Trust, 2008.

22. Lecky F, Mason S, Benger J, Cameron P, Walsh C. Framework for quality and safety in the emergency department. International Federation for Emergency Medicine, 2012. http://www.ifem.cc/site/ DefaultSite/filesystem/documents/Policies\%20and\%20Guidelines/Framework\%20for\%20Quality\%20 and $\% 20$ Safety\%20in\%20the\%20Emergency\%20Department\%202012.doc.pdf (accessed 18 August 2014).

Accepted 20 October 2014 


\begin{tabular}{|c|c|c|}
\hline Group & Panel member & Position \\
\hline \multicolumn{3}{|l|}{ Medical } \\
\hline $\begin{array}{l}\text { Emergency medicine academic } \\
\text { programme head }\end{array}$ & Prof. Efraim Kramer & University of the Witwatersrand \\
\hline $\begin{array}{l}\text { Emergency medicine academic } \\
\text { programme head }\end{array}$ & Prof. Dries Engelbrecht & University of Pretoria \\
\hline $\begin{array}{l}\text { Emergency medicine academic } \\
\text { programme head }\end{array}$ & Prof. Lee Wallis & Stellenbosch University/University of Cape Town \\
\hline $\begin{array}{l}\text { Emergency medicine academic } \\
\text { programme head }\end{array}$ & Dr William Lubinga & University of Limpopo \\
\hline $\begin{array}{l}\text { Emergency medicine academic } \\
\text { programme head }\end{array}$ & Dr Darryl Wood & University of KwaZulu-Natal \\
\hline Selected other medical doctors & Dr Hein Lamprecht & Head: Continuous Quality Improvement, Western Cape EMS \\
\hline Selected other medical doctors & Dr Roger Dickerson & SA College of Emergency Medicine \\
\hline Selected other medical doctors & Dr Basil Bonner & Emergency physician (private sector) \\
\hline Selected other medical doctors & Dr Tim Hardcastle & Trauma surgeon \\
\hline Selected other medical doctors & Dr Steve Holt & Emergency physician (private sector) \\
\hline Selected other medical doctors & Dr Niël van Hoving & Emergency physician \\
\hline Selected other medical doctors & Dr P H Hargovan & University of KwaZulu-Natal \\
\hline Selected other medical doctors & Dr Baljit Cheema & Paediatric emergency physician \\
\hline Selected other medical doctors & Dr Charl van Loggerenberg & Medical Director: International SOS \\
\hline Selected other medical doctors & Dr Mike Wells & Emergency physician \\
\hline Selected other medical doctors & Dr Wayne Smith & Head: Disaster Medicine (Western Cape) \\
\hline Selected other medical doctors & Dr Heike Geduld & Head: Education (Western Cape) \\
\hline Emergency medicine-related society & $\begin{array}{l}\text { Dr Jonathan Witt for Prof. Walter } \\
\text { Kloeck }\end{array}$ & $\begin{array}{l}\text { Head: Research task force team at Resuscitation Council of } \\
\text { South Africa }\end{array}$ \\
\hline Emergency medicine-related society & Dr Melanie Stander & Emergency Medicine Society of South Africa \\
\hline Emergency medicine-related society & Dr Elmin Steyn & Trauma Society of South Africa \\
\hline \multicolumn{3}{|l|}{ Nursing } \\
\hline Academic nursing institutions & Ms Jean Augustyn & Medi-Clinic \\
\hline Academic nursing institutions & $\begin{array}{l}\text { Ms Tanya Heyns on behalf of Prof. } \\
\text { Mulder }\end{array}$ & Senior lecturer: Emergency Nursing at University of Pretoria \\
\hline Academic nursing institutions & Ms S Schmollgruber for Prof. L Maree & Head: Nursing Education, University of the Witwatersrand \\
\hline Academic nursing institutions & Prof. S Duma & University of Cape Town \\
\hline Academic nursing institutions & Mande Toubkin & Netcare \\
\hline Academic nursing institutions & Prof. B Ncama & University of KwaZulu-Natal \\
\hline Academic nursing institutions & $\begin{array}{l}\text { Janet Bell on behalf of Prof. Marina } \\
\text { Clarke }\end{array}$ & Stellenbosch University \\
\hline Academic nursing institutions & Dr Doriccah Peu & University of Pretoria \\
\hline Academic nursing institutions & Dr Carin Maree & University of Pretoria \\
\hline Academic nursing institutions & Theo Lighthelm & School for Military Health Training \\
\hline Other nursing professionals & Prof. Petra Bryciewicz & Professional emergency care nurse \\
\hline Emergency medicine-related society & Lynette Thomas & Emergency care education \\
\hline Emergency medicine-related society & Kathy Bodmer & Emergency Nurses Society of South Africa \\
\hline Emergency medicine-related society & Yolande Magerman & Emergency Nurses Society of South Africa \\
\hline \multicolumn{3}{|l|}{ Policy makers } \\
\hline Prehospital directors & Dr Cleeve Robertson & Western Cape, EMS Director \\
\hline
\end{tabular}


Prehospital directors

Prehospital directors

Prehospital directors

Prehospital directors

National government

National government

Provincial government

Provincial government

Provincial government

Provincial government

Provincial government

Provincial government

Provincial government

Provincial government

Provincial government

Provincial government

Prehospital

Prehospital training programmes

Prehospital training programmes

Prehospital training programmes

Prehospital training programmes

Prehospital training programmes

Prehospital training programmes

Prehospital training programmes

Prehospital training programmes

Prehospital training programmes

Prehospital training programmes

Prehospital training programmes

Prehospital training programmes

Prehospital training programmes

Prehospital training programmes

Prehospital training programmes

Prehospital training programmes

Prehospital training programmes

Prehospital training programmes

Prehospital training programmes

Prehospital training programmes

Prehospital training programmes

Prehospital training programmes

Prehospital training programmes

Prehospital training programmes

Emergency medicine-related society

\author{
Mr N Sithole \\ Mr AK Munilal \\ Mr A Dhai \\ Mr T Dludlu \\ Mr Peter Fuhri \\ Dr Charles Theu \\ Dr Beth Engelbrecht \\ Dr Samuel Beja \\ Dr Theys \\ Dr Moji \\ Dr Nomonde Xundu \\ Dr Sibongiseni Dlomo \\ Dr Sibongile Zungu \\ Dr Clifford Mkasi \\ Dr Lydia Sebego \\ Dr Aggrey Morake
}

Ian Howard (on behalf of Cheryl

Pedersen)

Mr Raveen Naidoo

Mr W van der Net

Ms A Millum

Mr D J Taylor

Mr A Malgas

Ms Rosslyn Prinsloo

Mr Craig Lambert

Mr N C Gargan

Mr Ajesh Nundlall

Dr R Holgate

Mr K D Rowe-Rowe

Mr K Moodley

Mr L D Christopher

Mr S J Mfeka

Mr S Naguran

Mr A W Muller

Mr S M Makwala

Mr N M Zungu

Mr R Menkveld

Mr S Ramduth

Col I Bux

Mr A Keruparshad

Mr Adrian Trollip

Mr Cristopher Stein
KwaZulu-Natal, EMS Director

Free State, EMS Director

Northern Cape, EMS Director

Gauteng, EMS Director

National EMS, EMS Director

DoH National EMS Director

Western Cape: Deputy-Director General Health

Chief Directorate: Clinical Support, Eastern Cape

Head: Health, Northern Cape

Deputy Director-General, Free State

Head: Health, Gauteng

MEC Health, KZN

Head: Health, KZN

MEC Health, Mpumalanga

Head: Health, North West

Head: Health and Social Development, Limpopo

South African Air Mercy Service

Durban University of Technology

COJEMS Training Academy

Academy of Emergency Medical Training

Human Emergency Life Programme (H.E.L.P) Emergency

Medical Training

Lebone College of Emergency Care

Mankwe Ambulance Training Centre

University of Johannesburg

Ambutek

Central University of Technology, Free State

ER24

Free State College of Emergency Care

Western Cape College of Emergency Care

Cape Peninsula University of Technology

College of Emergency Care, KwaZulu-Natal

Durban University of Technology

Eastern Cape Ambulance Training College

Limpopo College of Emergency Care

Mpumalanga Ambulance Training College

North West Province EMS Rescue Services College

Netcare 911 School of Emergency and Critical Care

School for Military Health Training

Sharaj Training Service

Academy of Dynamic Emergency Training

Emergency Care Society of South Africa 